\title{
QUALIDADE FISIOLÓGICA E COMPOSIÇÃO QUÍMICA DAS SEMENTES DE SOJA COM VARIAÇÃONA COR DO TEGUMENTO ${ }^{1}$
}

\author{
ESMAELLOPES DOS SANTOS ${ }^{2}$, JOSÉNIVALDO PÓLA, ALBERTO SERGIO DO REGOBARROS ${ }^{3}$, CÁSSIO EGIDIO CAVENAGHI PRETE ${ }^{4}$
}

\begin{abstract}
RESUMO - A qualidade e a composição da semente de soja estão relacionadas com fatores genéticos, mas podem sofrer influência do meio ambiente. O tegumento, responsável pela proteção dos órgãos internos da semente, normalmente apresenta-se na cor amarela, mas pode sofrer variações de tonalidades através de mutação natural, podendo se apresentar marrom ou preto. $\mathrm{O}$ trabalho teve como objetivo verificar a qualidade fisiológica e a composição química das sementes de soja, quando ocorre a expressão da cor marrom no tegumento, em cultivares de soja Embrapa 48, BRS 156 e BRS 133. Para tanto, foi realizado teste de embebição, em intervalos de três horas num período de 24 horas; sendo a qualidade fisiológica avaliada através dos testes de germinação, envelhecimento acelerado e tetrazólio, e composição pela determinação da concentração de lignina e proteína. A expressão da cor marrom no tegumento das sementes, em uma mesma cultivar de soja, afeta positivamente a qualidade fisiológica, devido a menor velocidade de embebição e a sua composição química pela maior concentração de lignina e proteína.
\end{abstract}

Termos para indexação: Glycine max, embebição de semente, viabilidade, lignina e proteína.

\section{SOYBEAN SEED COAT VARIATIONAND ITS INFLUENCE ONTHE PHYSIOLOGICAL QUALITY AND CHEMICALCOMPOSITIOM}

\begin{abstract}
The quality and the composition of soybean seed are related to genetic factors, but they can be influenced by the environment. The seed coat, responsible for the protection of the internal organs of the seed, is normally yellow in color, but it can suffer variations from tonalities through natural mutation, showing brown or black color. The objective of this research was to verify the physiological quality and the chemical composition of soybean seeds, when the expression of brown color in the seed coat occurred, in the soybean cultivars such as Embrapa 48, BRS 156 and BRS 133. The imbibition test was carried out at three hour intervals in a 24 hour period; the physiological quality was evaluated by the following tests: germination, accelerated ageing and tetrazolium. The lignin percentage and protein concentration were determined. The expression of the brown color, in seeds of the same cultivar, affected the physiological quality positively, had the slowest imbebition speed and its chemical composition had the greatest concentration of lignin and protein content.
\end{abstract}

Index terms: Glycine max, imbebition of seed, viability, lignin and protein.

\section{INTRODUÇÃO}

A semente é responsável pela transferência de inovações tecnológicas e dos ganhos genéticos resultantes dos trabalhos de melhoramento, seja ele tradicional ou resultado da engenharia genética, até o campo. A qualidade da semente, definida como sendo o somatório de todos os atributos genéticos, físicos, fisiológicos e sanitários, é um dos principais

\footnotetext{
${ }^{1}$ Submetido em 05/01/2006. Aceito para publicação em 25/08/2006.

${ }^{2}$ Biólogo, Mestrando do Departamento de Agronomia - UEL, e.lopes@sercomtel.com.br

${ }^{3}$ Eng. Agr. Ms. Área de Propagação Vegetal - IAPAR, Caixa Postal 481,
}

86001-970, Londrina-PR, pola@iapar.br, asbarros@iapar.br

${ }^{4}$ Eng. Agr. Dr. Professor Associado do Departamento de Agronomia - UEL, Caixa Postal 6001, 86051-990, Londrina-PR, cassio@uel.br 
fatores na determinação do sucesso de uma cultura (Vieira, 1980). Esses atributos são em grande parte reflexos das funções do tegumento da semente de soja (Silva, 2003).

A semente da soja apresenta o tegumento que pode sofrer variações de tonalidades, dependente de uma série de alelos $\underline{\mathrm{I}}$, $\underline{i}^{\mathrm{i}}, \underline{\mathrm{i}}^{\mathrm{k}}$ e o gene $\underline{\mathrm{i}}$ que controla a distribuição dos pigmentos que se localizam na camada paliçadica da epiderme da semente. A semente é inteiramente preta ou marrom na presença do alelo

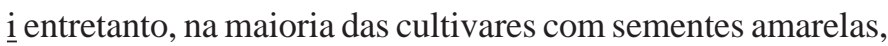
isto é, com constituição I ou $\underline{i}^{\mathrm{i}}$, freqüentemente encontram-se sementes coloridas de preto ou marrom, isso ocorre através de mutação de I ou ị para $\underline{\text { i. }}$ (Carvalho e Nakagawa, 1988).

A alteração da expressão do gene "I" tem apresentado características distintas em sua série alélica, alterando outras características da semente quando expressado a cor preta no tegumento. De acordo com Webb et al. (1995), esta região apresenta-se associada com caracteres relacionados à tolerância a nematóides formadores de galhas, e para Mansur et al. (1998), a região também esta associada a stresse causado na planta por fatores ambientais, entre eles à tolerância a seca.

Os principais componentes químicos das sementes, responsáveis pela embebição, são as proteínas, e, em menor intensidade, a celulose e substâncias pécticas; o amido e os lipídios apresentam interferência reduzida no processo (Mayer e Mayber, 1978; Copeland e McDonald, 1995). Alguns autores também atribuem a determinação da composição da semente de soja por fatores genéticos, mas que podem sofrer influências ambientais durante o seu cultivo (Burton et al., 1995; Westgate et al.,1995). Tavares et al. (1986), sugerem que tegumentos escuros atrasam o processo de embebição, e tegumentos com alto teor de lignina podem influenciar a embebição.

A ocorrência de diferenças no grau de permeabilidade do tegumento, também levou pesquisadores a determinarem a possível ocorrência de materiais hidrófobos na camada paliçádica. Foi observado por França Neto et al. (1999), maior quantidade de lignina nos tegumentos de linhagens com sementes de coloração escura, $12,18 \%$, ao passo que as linhagens de tegumento amarelo apresentaram 4,75\%. Os autores observaram que as sementes com maior quantidade de lignina apresentaram melhor qualidade das sementes. No entanto, Giurizatto et al. (2003), estudando o efeito da época de colheita sobre a viabilidade e o vigor das sementes de soja, utilizando cultivares com tonalidades diferentes de tegumento, verificaram que algumas cultivares com sementes de tegumento amarelo apresentavam qualidade fisiológica superior ao das cultivares com sementes de tegumento marrom e preto. Estes trabalhos sugerem que as características de qualidade fisiológica e composição não sejam determinadas somente pela alteração da cor do tegumento, mas sim pela genética da cultivar que apresenta a mutação.

Desta forma, o objetivo do trabalho foi verificar a qualidade fisiológica e a composição química das sementes de soja, quando ocorre a expressão da cor marrom no tegumento, em cultivares de soja Embrapa 48, BRS 156 e BRS 133.

\section{MATERIALE MÉTODOS}

Em campos de produção de sementes de soja das cultivares Embrapa 48, BRS 156 e BRS 133 conduzidos na região de Ponta Grossa-PR, na safra 2002/2003, foram encontradas durante o beneficiamento, mutantes naturais, cujo tegumento se apresenta na cor marrom.

A multiplicação das sementes para a realização dos trabalhos foi realizada na estação experimental do Instituto Agronômico do Paraná - IAPAR, em Londrina-PR, na safra 2003/2004. O delineamento experimental adotado foi o de blocos ao acaso com três repetições. As parcelas foram compostas de quatro linhas de cinco metros de comprimento, e espaçamento de $0,45 \mathrm{~m}$ nas entrelinhas com densidade de 12 plantas. $\mathrm{m}^{-1}$, colhendo-se quatro metros de cada uma das duas linhas centrais, resultando em área útil de $3,6 \mathrm{~m}^{2}$, e área total de $9,0 \mathrm{~m}^{2}$. A semeadura foi efetuada com a semeadora de parcelas da SEMEATO, modelo SHPA 249/04 EA, em solo Latossolo vermelho escuro, com adubação de base de $280 \mathrm{~kg}$ $\mathrm{ha}^{-1}$ da formula 04-30-10, em plantio direto. O manejo de pragas, doenças e medidas de controle, assim como plantas daninhas, foram realizados conforme Embrapa Soja (2001). As sementes foram colhidas manualmente e trilhadas em trilhadeira estacionária.

Os testes de fisiologia de sementes foram realizados no laboratório de propagação vegetal do IAPAR e as análises de composição química, em laboratórios do Centro de Ciências Agrárias da Universidade Estadual de Londrina-PR.

Foram selecionadas amostras de sementes, sem danos visíveis no tegumento através de lupa, das cultivares Embrapa 48 e BRS 133. A cultivar BRS 156, apresentou uma taxa de $80 \%$ das sementes com o tegumento trincado, inviabilizando sua utilização para o teste de embebição.

A determinação da porcentagem de embebição de água pelas sementes foi realizada de forma semelhante ao teste padrão de germinação, sendo efetuada com 24 repetições de 50 sementes de cada cultivar. As amostras foram pesadas em 
balança de precisão para determinação do peso inicial, e envolvidas em rolo de papel umidecido, que posteriormente foram condicionadas em estufa a $25^{\circ} \mathrm{C}$. Em intervalos de três horas num período de 24 horas, três repetições de cada cultivar, foram retiradas da estufa, enxutas em papel-toalha e pesadas para a obtenção do peso final e da porcentagem de embebição de água, utilizando a fórmula: \% $\mathrm{E}=[(\mathrm{PF}-\mathrm{PI}) / \mathrm{PI}]$ $\mathrm{X} 100$, em que $\% \mathrm{E}=$ porcentagem de embebição, $\mathrm{PF}=$ peso final da amostra e PI = peso inicial da amostra, e os resultados expressos em porcentagem.

O teste de germinação foi conduzido com 3 repetições de 50 sementes, sendo as sementes colocadas para germinar em rolo de papel úmido, num germinador a $25^{\circ} \mathrm{C}$ e em torno de $90 \%$ de umidade relativa, por um período de cinco dias. As avaliações foram realizadas de acordo com as Regras para Análise de Sementes (Brasil, 1992).

A metodologia adotada para o teste de envelhecimento acelerado foi baseada na descrita por Marcos Filho et al. (1987), utilizando-se uma minicâmara na qual foram colocadas 3 repetições de 50 sementes de cada tratamento sobre uma tela localizada a $2 \mathrm{~cm}$ do fundo do gerbox, adicionando-se $40 \mathrm{~mL}$ de água no seu interior. A seguir, foram levadas para a câmara de envelhecimento acelerado, regulada a uma temperatura de $42^{\circ} \mathrm{C}$ e $95 \%$ de umidade relativa, por um período de 72 horas. Retiradas da câmara, as sementes foram colocadas para germinar, e avaliadas conforme o teste de germinação.

O potencial de viabilidade e o vigor das sementes avaliados pelo teste de tetrazólio foram determinados com 3 repetições de 50 sementes para cada tratamento. As sementes préacondicionadas em papel úmido por um período de 16 horas foram imersas em solução $0,075 \%$ de 2,3,5- trifenil cloreto de tetrazólio, e mantidas em estufa a $36^{\circ} \mathrm{C}$ por três horas para a coloração. Em seguida, foram lavadas e avaliadas individualmente, conforme os critérios estabelecidos por França Neto et al. (1994).

Para a determinação de concentração de lignina e da proteína, utilizaram-se amostras de cada uma das três repetições do experimento conduzido no campo.

Para determinar a concentração de lignina nas sementes, foi utilizando o método sugerido por Alvarez et al. (1997), onde as sementes foram inicialmente submersas em água, por aproximadamente 12 horas, em um becker de $50 \mathrm{~mL}$, em seguida o tegumento foi separado do cotilédone, e submetido a desidratação em estufa à temperatura de $105^{\circ} \mathrm{C}$ por 16 horas. Posteriormente o tegumento foi moído e passado em tamize, sendo 250 gramas do material com granulação de 60 mesh, transferido para um frasco de $250 \mathrm{~mL}$, adicionado $50 \mathrm{~mL}$ de etanol $80 \%(\mathrm{p} / \mathrm{v})$ e aquecido a $100^{\circ} \mathrm{C}$ sob refluxo por 10 minutos. As amostras foram filtradas e o sedimento transferido para o frasco descrito acima e adicionado $100 \mathrm{~mL}$ de água destilada deionizada e aquecido sob refluxo por 10 minutos. A seguir, as amostras foram filtradas e o sedimento foi transferido para o frasco e adicionado $100 \mathrm{~mL}$ de oxalato de amônio $0,5 \%(\mathrm{p} / \mathrm{v})$. Os frascos foram aquecidos por 2 horas sob refluxo. As amostras foram filtradas e o sedimento transferido para um frasco de vidro. Foi adicionado $100 \mathrm{~mL}$ de ácido sulfúrico $1 \mathrm{~N}$ e aquecido por 2 horas sob refluxo. Depois, as amostras foram filtradas em cadinho com vidro sinterizado. Os resíduos foram lavados com $50 \mathrm{~mL}$ de acetona e transferidos para um becker. Foi adicionado $20 \mathrm{~mL}$ de ácido sulfúrico $72 \%$ (p/v) e deixado em repouso por 12 horas. Após este período, as amostras foram hidrolisadas e transferidas para frascos de $250 \mathrm{~mL}$ e adicionado $100 \mathrm{~mL}$ de água destilada deionizada, e aquecido por 2 horas sob refluxo. Após este tratamento, os resíduos foram filtrados em cadinhos com vidro sinterizado sob vácuo. Os resíduos foram lavados com $200 \mathrm{~mL}$ de água destilada e secados a $105^{\circ} \mathrm{C}$ por 6 horas. A porcentagem de lignina das sementes foi determinada gravimetricamente.

Para a determinação da concentração de proteína, foi utilizado o método de Kjeldahl, conforme descrito por Pregnolatto e Pregnolatto (1985), que se baseia na digestão da amostra por ácido sulfúrico para eliminação de todos os componentes orgânicos, transformando o nitrogênio amínico das proteínas em sal (sulfato de amônia). O sulfato de amônia é separado da solução de digestão por destilação em meio alcalino, captado em solução de ácido e titulado. Obtém-se a quantidade de proteína correspondente ao nitrogênio titulado, por cálculo, aplicando-se o seguinte fator de conversão: $\%$ Nitrogênio $=\mathrm{V} \times \mathrm{N}(0,02) \times \mathrm{fc} \times 0,014$ x 100/p.a., em que $\mathrm{V}=$ volume de $\mathrm{H}_{2} \mathrm{SO}_{4} 0,02 \mathrm{~N}$ gasto na titulação, $\mathrm{N}=$ normalidade da solução titulante, fc $=$ fator de correção da solução titulante e p.a. = peso da amostra.

\section{RESULTADOS E DISCUSSÃO}

A Tabela 1 apresenta os resultados da embebição das sementes, onde observa-se que as sementes com tegumento de cor amarela da cultivar Embrapa 48 sempre apresentaram maior quantidade de água absorvida quando comparadas as sementes da mesma cultivar com tegumento marrom. Para as sementes da cultivar BRS 133, não houve diferença significativa até o período de $9 \mathrm{~h}$, após este período, as 
TABELA 1. Água embebida (\%) pelas sementes de soja, submetidas a oito períodos de embebição em intervalos de três horas, em relação ao peso inicial.

\begin{tabular}{|c|c|c|c|c|c|c|c|c|c|}
\hline \multirow{2}{*}{ Cultivar } & \multirow{2}{*}{ Tegumento } & \multicolumn{8}{|c|}{ Tempo de embebição } \\
\hline & & $3 \mathrm{hs}$ & $6 \mathrm{hs}$ & $9 \mathrm{hs}$ & $12 \mathrm{hs}$ & $15 \mathrm{hs}$ & $18 \mathrm{hs}$ & $21 \mathrm{hs}$ & $24 \mathrm{hs}$ \\
\hline Embrapa 48 & Amarelo & $15,65^{1} \mathrm{~A}$ & $27,84 \mathrm{~A}$ & $38,12 \mathrm{~A}$ & $46,53 \mathrm{~A}$ & $62,16 \mathrm{~A}$ & $74,18 \mathrm{~A}$ & $80,52 \mathrm{~A}$ & $87,01 \mathrm{~A}$ \\
\hline Embrapa 48 & Marrom & $14,40 \mathrm{~B}$ & $26,99 \mathrm{~B}$ & $36,44 \mathrm{~B}$ & $44,83 \mathrm{~B}$ & $60,36 \mathrm{~B}$ & 67,97 B & $75,05 \mathrm{~B}$ & 84,99 B \\
\hline \multicolumn{10}{|l|}{$\begin{array}{l}\text { CV1\% }=0,24 \\
\text { CV2\% }=0,30\end{array}$} \\
\hline BRS 133 & Amarelo & $12,44^{1} \mathrm{~A}$ & $26,90 \mathrm{~A}$ & $34,15 \mathrm{~A}$ & $45,37 \mathrm{~A}$ & $59,35 \mathrm{~A}$ & $75,37 \mathrm{~A}$ & $75,17 \mathrm{~A}$ & $89,52 \mathrm{~A}$ \\
\hline BRS 133 & Marrom & $12,42 \mathrm{~A}$ & $26,05 \mathrm{~A}$ & $33,81 \mathrm{~A}$ & $42,12 \mathrm{~B}$ & $53,31 \mathrm{~B}$ & $65,35 \mathrm{~B}$ & $71,61 \mathrm{~B}$ & $80,51 \mathrm{~B}$ \\
\hline \multicolumn{10}{|l|}{$\begin{array}{l}\text { CV1\% }=2,64 \\
\text { CV2\% }=2,48\end{array}$} \\
\hline Cultivar & Tegumento & & Regressãc & & & p-valor & & $r^{2}$ & \\
\hline Embrapa 48 & Amarelo & & $=6,50+3$, & & & $<0,001$ & & 0,9895 & \\
\hline Embrapa 48 & Marrom & & $=6,13+3$, & & & $<0,001$ & & 0,9933 & \\
\hline BRS 133 & Amarelo & & $=3,08+3$, & & & $<0,001$ & & 0,9844 & \\
\hline BRS 133 & Marrom & & $=4,74+3,2$ & & & $<0,001$ & & 0,9951 & \\
\hline
\end{tabular}

${ }^{1}=$ Médias seguidas de mesma letra, não diferem a 5\% de probabilidade pelo Teste de Tukey

sementes de tegumento da cor marrom apresentaram uma menor porcentagem de embebição.

Quando realizado a regressão, foi possível verificar uma correlação positiva entre à capacidade de embebição de água e o tempo de embebição, além de separar os tegumentos quanto a porcentagem de água absorvida, mostrando que tanto na cultivar Embrapa 48 quanto na BRS 133, as sementes com o tegumento marrom absorveram menos que as de tegumento amarelo (Figuras 1 e 2).

A característica de maior ou menor embebição pelo

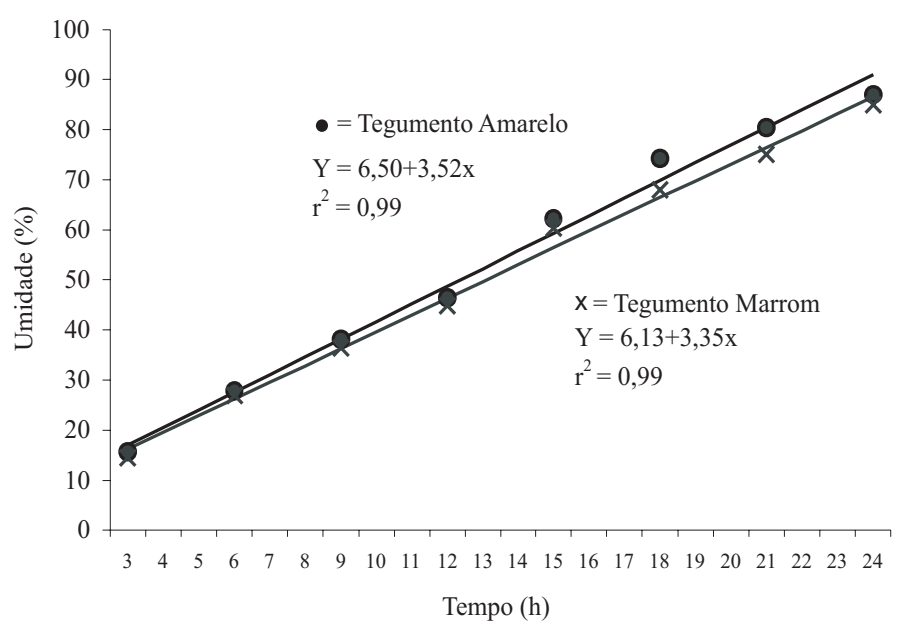

FIGURA 1. Água absorvida pela cultivar Embrapa 48 com variação na cor do tegumento, em função do tempo de embebição. tegumento, pode ser explicada pela composição do mesmo (Tabela 2), conforme as diferenças na concentração de lignina entre os tegumentos marrom e amarelo. A lignificação do tegumento é uma característica relevante, pois confere resistência mecânica ao tecido e protege a parede celulósica do ataque de microorganismos. Para Alvarez et. al. (1997), há relação direta entre a resistência aos danos mecânicos e o teor de lignina no tegumento das sementes de soja, determinando comportamento diferencial entre as cultivares. Os autores ainda afirmam, que o conteúdo de lignina no

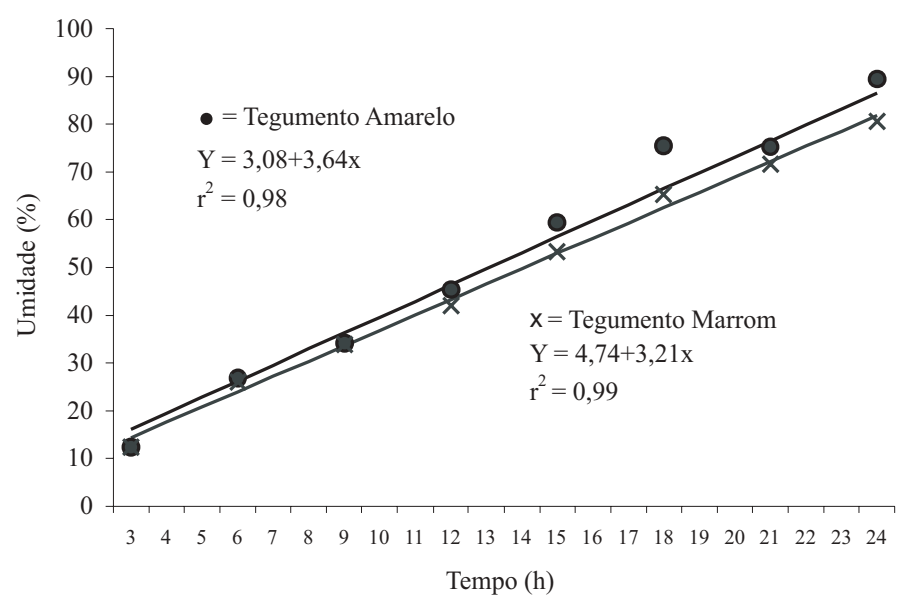

FIGURA 2. Água absorvida pela cultivar BRS 133 com variação na cor do tegumento, em função do tempo de embebição. 
TABELA 2. Valores médios (\%) de lignina em relação ao peso total do tegumento.

\begin{tabular}{lcc}
\hline \multirow{2}{*}{ Cultivar } & \multicolumn{2}{c}{ Cor do tegumento } \\
\cline { 2 - 3 } & Amarela & Marrom \\
\hline BRS 48 & 2,5 & 5,2 \\
BRS 156 & 2,3 & 4,4 \\
BRS 133 & 2,9 & 6,0 \\
\hline Média & 2,6 & 5,2 \\
\hline
\end{tabular}

tegumento da semente de soja apresenta-se maior nas cultivares com maior resistência ao dano mecânico, sugerindo que valores superiores a 5\% de lignina no tegumento são bons indicativos de sementes com resistência ao dano mecânico.

No teste de germinação (Tabela 3), pode-se verificar que as sementes com tegumento marrom apresentaram as maiores médias. No entanto, não houve diferença significativa nas cultivares BRS 133 e BRS 156 com tegumento marrom. O mesmo não ocorreu com a cultivar Embrapa 48, que apresentou diferença significativa entre os tegumentos com valores inferiores para o tegumento amarelo. Entre as cultivares estudadas, somente as cultivares BRS 133 e Embrapa 48, apresentaram diferenças significativas nas porcentagens de germinação das sementes com tegumento amarelo. Para o tegumento marrom, não houveram diferenças significativas entre as cultivares estudadas. $\mathrm{O}$ fato das sementes com tegumento marrom apresentarem as maiores médias, pode estar relacionado também com o maior conteúdo de lignina. Panobianco et. al. (1999), verificaram que o maior conteúdo de lignina, influencia em uma menor troca de solutos entre a semente e o ambiente externo, alterando assim os níveis de condutividade elétrica que refletem na qualidade fisiológica da semente.

Para a viabilidade das sementes apresentadas pelo teste de tetrazólio (Tabela 4), não foi possível verificar diferenças significativas dos caracteres estudados. Os níveis de vigor

TABELA 3. Valores médios (\%) do teste de germinação de três cultivares, em função da cor do tegumento.

\begin{tabular}{lccc}
\hline \multirow{2}{*}{ Cultivar } & \multicolumn{2}{c}{ Cor do tegumento } & \multirow{2}{*}{ Média } \\
\cline { 2 - 3 } & Amarelo & Marrom & \\
\hline BRS 133 & $93,5^{1} \mathrm{aA}$ & $96,0 \mathrm{aA}$ & 94,5 \\
BRS 156 & $90,0 \mathrm{aAB}$ & $95,0 \mathrm{aA}$ & 92,5 \\
Embrapa 48 & $86,5 \mathrm{bB}$ & $92,5 \mathrm{aA}$ & 89,5 \\
\hline Média & 90,0 & 94,5 & - \\
CV\% $\%$ 3,87 & & &
\end{tabular}

${ }^{1}=$ Médias seguidas de mesma letra, maiúscula na coluna e minúscula na linha, não diferem a 5\% de probabilidade pelo Teste de Tukey
TABELA 4. Valores médios (\%) do potencial de viabilidade do teste de tetrazólio de três cultivares de soja, em função da cor do tegumento.

\begin{tabular}{lccc}
\hline \multirow{2}{*}{ Cultivar } & \multicolumn{2}{c}{ Cor do tegumento } & \multirow{2}{*}{ Média } \\
\cline { 2 - 3 } & Amarelo & Marrom & \\
\hline BRS 156 & $92,0{ }^{1}$ aA & 97,0 aA & 94,5 \\
BRS 133 & 92,0 aA & 95,0 aA & 93,5 \\
Embrapa 48 & 91,0 aA & 94,0 aA & 92,5 \\
\hline Média & 91,7 & 95,3 & - \\
CV\%=3,86 & & & \\
\hline
\end{tabular}

${ }^{1}=$ Médias seguidas de mesma letra, maiúscula na coluna e minúscula na linha, não diferem a $5 \%$ de probabilidade pelo Teste de Tukey

das sementes obtidos pelo teste de tetrazólio (Tabela 5), não apresentaram diferenças significativas entre as cultivares, porém, as médias diferem indicando maior vigor para as sementes que apresentam o tegumento de cor marrom.

O teste de envelhecimento acelerado (Tabela 6), apresentou valores de vigor com diferenças significativas entre as cultivares e entre os tegumentos. Neste caso a cultivar BRS 133, foi a que apresentou os maiores valores entre as cultivares e entre os tegumentos, sendo que entre os tegumentos nesta cultivar, não houve diferença significativa. A cultivar Embrapa 48 foi a que apresentou os menores valores de vigor entre as cultivares, e diferiu-se entre os tegumentos

TABELA 5. Valores médios (\%) de vigor do teste de tetrazólio de três cultivares de soja, em função da cor do tegumento.

\begin{tabular}{lccc}
\hline \multirow{2}{*}{ Cultivar } & \multicolumn{2}{c}{ Cor do tegumento } & \multirow{2}{*}{ Média } \\
\cline { 2 - 3 } & Amarelo & Marrom & \\
\hline BRS 156 & $78,0^{1}$ & 85,0 & $81,5 \mathrm{~A}$ \\
Embrapa 48 & 68,0 & 81,0 & $74,5 \mathrm{~A}$ \\
BRS 133 & 69,0 & 76,0 & $72,5 \mathrm{~A}$ \\
\hline Média & $71,7 \mathrm{~b}$ & $80,7 \mathrm{a}$ & -
\end{tabular}

Média

${ }^{1}$ = Médias seguidas de mesma letra, maiúscula na coluna e minúscula na linha, não diferem a $5 \%$ de probabilidade pelo Teste de Tukey

TABELA 6. Valores médios (\%) de vigor do teste de envelhecimento acelerado de três cultivares de soja, em função da cor do tegumento.

\begin{tabular}{lccc}
\hline \multirow{2}{*}{ Cultivar } & \multicolumn{2}{c}{ Cor do tegumento } & \multirow{2}{*}{ Média } \\
\cline { 2 - 3 } & Amarelo & Marrom & \\
\hline BRS 133 & $91,0 \mathrm{aA}$ & $94,0 \mathrm{aA}$ & 92,7 \\
BRS 156 & $83,0 \mathrm{aB}$ & $83,0 \mathrm{aB}$ & 83,0 \\
Embrapa 48 & $79,5 \mathrm{bB}$ & $86,0 \mathrm{aB}$ & 82,7 \\
\hline Média & 84,5 & 87,8 & - \\
CV\% $=4,85$ & & & \\
\hline
\end{tabular}

${ }^{1}=$ Médias seguidas de mesma letra, maiúscula na coluna e minúscula na linha, não diferem a $5 \%$ de probabilidade pelo Teste de Tukey 
onde as sementes com tegumento marrom apresentaram um vigor superior às de tegumento amarelo.

As concentrações de proteína observadas apresentamse com baixas variações entre as cultivares. As sementes da cultivar Embrapa 48 apresentaram concentrações de proteína significativamente maiores que as cultivares BRS 156 e BRS 133, essas por sua vez, não diferem estatisticamente (Tabela 7). A cultivar Embrapa 48 também apresenta concentração de proteína significativa para o tegumento de cor marrom sobre a mesma cultivar com o tegumento de cor amarela, o mesmo ocorre com a cultivar BRS 156. Já para a cultivar BRS 133, as concentrações de proteína não diferem entre os tegumentos de cor marrom e amarela.

TABELA 7. Valores médios obtidos da concentração de proteína ${ }^{1}$ em sementes de três cultivares de soja, em função da cor do tegumento.

\begin{tabular}{lllc}
\hline \multirow{2}{*}{ Cultivar } & \multicolumn{2}{c}{ Cor do tegumento } & \multirow{2}{*}{ Média } \\
\cline { 2 - 3 } & Amarelo & Marrom & \\
\hline Embrapa 48 & $34,3^{2} \mathrm{Ab}$ & $36,7 \mathrm{Aa}$ & 35,6 \\
BRS 156 & $33,0 \mathrm{Bb}$ & $34,0 \mathrm{Ba}$ & 33,5 \\
BRS 133 & $32,9 \mathrm{Ba}$ & $33,4 \mathrm{Ba}$ & 33,2 \\
\hline Média & 33,5 & 34,7 & - \\
CV\%=1,02 & & & \\
\hline
\end{tabular}

${ }^{1}=$ Base seca

${ }^{2}=$ Médias seguidas de mesma letra, maiúscula na coluna e minúscula na linha, não diferem a 5\% de probabilidade pelo Teste de Tukey

Embora nos testes realizados, alguns dados não apresentaram diferenças significativas, ainda assim é possível verificar que os valores obtidos nas sementes de soja de tegumento marrom são maiores que os apresentados pelas sementes de tegumento de cor amarela, quando comparados em uma mesma cultivar. No entanto, não foi possível verificar uma separação entre os tegumentos marrom e amarelo, estas diferenças apresentadas podem estar ligadas às características das cultivares estudadas.

\section{CONCLUSÃO}

A expressão da cor marrom no tegumento das sementes, em uma mesma cultivar de soja, afeta positivamente a qualidade fisiológica, devido a menor velocidade de embebição e à sua composição química pela maior concentração de lignina e proteína.

\section{REFERÊNCIAS}

ALVAREZ, P.J.C.; KRZYZANOWSKI, F.C.; MANDARINO, J.M.G.; FRANÇA NETO, J.B. Relationship between soybean seed coat lignin content and resistance to mechanical damage. Seed Science and Technology, Zürich, v.25, n. 2. p.209-214, 1997.

BRASIL. Ministério da Agricultura e da Reforma Agrária. Regras para análise de sementes. Brasília: SNDA/DNDV/CLAV, 1992. $365 \mathrm{p}$.

BURTON, J.W.; ISREAL, D.W.; WILSON, R.F.; CARTER, T.E. Effects of defoliation on seed protein concentration in normal and high protein lines of soybean. Plant and Soil, Holanda, v. 172, n. 1, p. 131-139, 1995.

CARVAlho, N. M.; NAKAGAWA, J. Sementes: ciência, tecnologia e produção. 3 ed. Campinas: Fundação Cargill, 1988. $428 \mathrm{p}$.

COPELAND, L.O.; McDONALD, M.B. Principles of seed science and technology. 3. ed. New York: Chapman e Hall, 1995. 409p.

EMPRESA BRASILEIRA DE PESQUISA AGROPECUÁRIA. Tecnologia de produção de soja - Paraná - 2001/2002. Londrina: Embrapa/soja, 2001. 281p. ( Documento, 166)

FRANÇA NETO, J. B.; KRZYZANOWSKI, F. C.; WEST, S. H.; HENNING, A. A.; COSTA, N. P. Determinação do conteúdo de lignina nos tegumentos de sementes de soja com tegumento preto e amarelo. In: REUNIÃO DE PESQUISA DE SOJA DA REGIÃO CENTRAL DO BRASIL, 21., 1999, Londrina. Anais... Londrina: Embrapa Soja, 1999. 247 p. ( Documento, 134)

FRANÇA NETO, J. B.; PEREIRA, L. A. G.; COSTA, N. P.; KRZYZANOWISKI, F. C.; HENNING, A. A. Metodologia do teste de tetrazólio em sementes de soja. Londrina: EMBRAPA/CNPSo, $1994.59 \mathrm{p}$.

GIURIZATTO, M. I. K.; SOUZA, L. C. F.; ROBAINA, A. D.; GONÇALVES, M. C. Efeito da época de colheita e da espessura do tegumento sobre a viabilidade e o vigor de sementes de soja Ciência e Agrotecnologia, Lavras. v.27, n.4, p.771-779, 2003.

MANSUR, L. K.G. LARK, AND J. ORF. Results of seven years of QTL mapping using three sets of recombinant inbred lines of soybean (Glycine max L.). In: SYMPOSIUM OF MOLECULAR AND CELLULAR BIOLOGY OF THE SOYBEAN, 1998, Knoxville, TN. Proceedings...University of Tennessee, 1998. p. F7.

MARCOS FILHO, J.; CÍCERO, S. M.; SILVA, W. R. Avaliação da qualidade das sementes. Piracicaba: FEALQ, 1987. 230 p.

MAYER, A.M.; MAYBER, A.P. The germination of seeds. 2.ed. Oxford: Pergamon Press, 1978. 192p.

PANOBIANCO, M.; VIEIRA, R.D.; KRZYZANOWSKI, F. C.; FRANÇA NETO, J. B. Electrical condutivity of soybean seed and correlation with seed coat lignin content. Seed Science and Technology, v. 27, n. 3, p. 945-949, 1999.

PREGNOLATTO, W.; PREGNOLATTO, N.P. (Coord.). Normas analíticas do Instituto Adolfo Lutz. v.1, 3.ed. São Paulo: Instituto Adolfo Lutz, 1985 p.25-26; 42-45. 
SILVA, M. A. D. Anatomia do tegumento de sementes de soja avaliadas com microscopia eletrônica de varredura. 2003. 88f. Tese (Doutorado em Produção e Tecnologia de Sementes), Universidade Estadual de São Paulo, Jaboticabal, 2003.

TAVARES, D.Q.; UMINO, C.Y.; DIAS, G.M.; MIRANDA, M.A.C. Compostos fenólicos no tegumento de sementes de linhagens de soja permeável e impermeável. Revista Brasileira de Botânica, São Paulo, v.9, n. 2, p.167-171, 1986.

VIEIRA, R. D. Avaliação da qualidade fisiológica de sementes de quatorze cultivares de soja (Glycine max (L) Merrill). 1980. $76 \mathrm{f}$. Dissertação (Mestrado em Fitotecnia) - Universidade Federal de
Viçosa, Viçosa, 1980.

WEBB, D.M.; BALTAZAR, B.M.; RAO ARELLI, A.P.; SCHUPP, J.; CLAYTON, K.; KEIMW, P.; BEAVIS, D. Genetic mapping of soybean cyst nematode race-3 resistance loci in the soybean PI 437654. Theoretical and Applied Genetics, Arizona, v. 91, n 4, p. 574-581, 1995.

WESTGATE, M.E.; ORF, J.; SCHUSSLER, J.R.; SHUMWAY, C. Temperture regulation of uptake and metabolism of protein and oil precursors by developing soybean embryos. Madison: American Soybean Association, 1995. 106p. (Agronomy Abstracts)

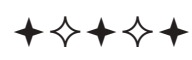

